\title{
AS CONTRIBUIÇÕES DO LÚDICO PARA O DESENVOLVIMENTO EMOCIONAL INFANTIL NO CONTEXTO ESCOLAR
}

Rafaela Reginato Hosokawa, Andréia Cristiane Silva Wiezzel

Pedagogia, Departamento de Educação, Faculdade de Ciências e Tecnologia- UNESP. E-mail: rafaela_reginato@hotmail.com

\section{RESUMO}

Segundo Winnicott (1982), o brincar representa uma forma de comunicação através da qual a criança revela seus sentimentos, simboliza e elabora seus conflitos e manifesta a sua realidade interior. Considerando que as crianças em idade escolar enfrentam conflitos internos que podem interferir em seu desempenho escolar e comportamento, este artigo pretende discutir de que maneira as atividades lúdicas podem auxiliar o desenvolvimento emocional na infância, tendo como suporte as teorias da Psicanálise sobre a importância do brincar para a simbolização e resolução dos conflitos infantis. Portanto, a partir da perspectiva psicanalítica, busca-se refletir sobre os benefícios da presença da ludicidade no espaço escolar, especialmente para alunos com dificuldades de relacionamento e de aprendizagem decorrentes de causas emocionais.

Palavras-chave: Brincar; infância; Psicanálise; conflitos emocionais; espaço escolar.

\section{INTRODUÇÃO E OBJETIVO}

O processo de ensino e aprendizagem é complexo e dele fazem parte diversos fatores, dentre os quais estão presentes os aspectos emocionais, que podem ser responsáveis por dificuldades de relacionamento e de aprendizagem em sala de aula. Os conflitos emocionais e psicológicos dos alunos podem configurar grandes dificuldades para os professores, pois estes, na maioria das vezes, não tiveram uma formação específica para lidar com tais questões.

Os conflitos manifestados em sala de aula podem ser resolvidos de diversas maneiras, porém, pesquisas apontam que, na infância, uma das formas mais eficientes para auxiliar a criança em seu desenvolvimento emocional é o brincar (FREUD, 1976; KLEIN, 1991; ABERASTURY, 1992; WINNICOTT, 1975, 1982, 2005).

Nessa perspectiva, no presente artigo pretende-se discutir de que maneira as atividades lúdicas podem auxiliar o desenvolvimento emocional na infância, do ponto de vista da teoria psicanalítica, buscando, assim, refletir sobre o papel do lúdico como beneficiador do processo de ensino e aprendizagem.

\section{METODOLOGIA}

A presente pesquisa se insere em uma abordagem qualitativa que, de acordo 
com o que apresentam Bogdan e Biklen (1982 apud LÜDKE; ANDRÉ 1986, p.13), “[...] envolve a obtenção de dados descritivos, obtidos no contato direto do pesquisador com a situação estudada, enfatiza mais o processo do que o produto e se preocupa em retratar a perspectiva dos participantes".

Para atingir os objetivos propostos realizou-se um levantamento bibliográfico acerca do tema proposto, procurando investigar quais benefícios o brincar pode trazer ao desenvolvimento emocional na infância e, consequentemente, ao processo de aprendizagem, de acordo com a abordagem psicanalítica.

\section{RESULTADOS}

A ludicidade pode ser entendida de inúmeras formas. Este trabalho baseia-se nos pressupostos da teoria psicanalítica acerca do brincar como uma possibilidade de simbolização e elaboração dos conflitos infantis.

Freud (1976) compreende o brincar como um mecanismo psicológico que permite à criança criar um mundo que atenda aos seus desejos e necessidades, no qual poderá repetir suas vivências, assim como fazer coisas que não estão ao seu alcance.

É claro que em suas brincadeiras as crianças repetem tudo que Ihes causou uma grande impressão na vida real, e assim procedendo, ab-reagem à intensidade da impressão, tornando-se, por assim dizer, senhoras da situação. Por outro lado, porém, é óbvio que todas as suas brincadeiras são influenciadas por um desejo que as domina o tempo todo: o desejo de crescer e poder fazer o que as pessoas crescidas fazem. (FREUD, 1976, p. 27).

Klein (1991), em seu artigo A técnica psicanalítica através do brincar, reflete acerca da terapia psicanalítica com crianças, entendendo as atividades lúdicas como "[...] meios de expressar o que o adulto expressa predominantemente através de palavras". (KLEIN, 1991, p.151) Klein (1991) considera que o brinquedo apresenta-se à criança como um instrumento que permite uma comunicação de forma abrangente, possuindo um significado semelhante ao dos sonhos para a Psicanálise.

Para Winnicott (1975), a atividade lúdica assume naturalmente uma função terapêutica para a criança, mesmo que não se trate de um atendimento clínico ou de uma terapia em sentido estrito. Winnicott $(1975$, p.74) ressalta que "É bom recordar que o brincar é por si mesmo uma terapia. Conseguir que as crianças possam brincar é em si mesmo uma psicoterapia que possui aplicação imediata e universal [...]". Conforme Winnicott (1982), o brincar não 
representa para a criança apenas uma atividade prazerosa, mas também, um momento que propicia o domínio e a expressão de suas angústias.

Frequentemente, a angústia é um dos aspectos que motiva e predomina nas brincadeiras infantis. Segundo Aberastury (1992), a criança encontra no brinquedo uma maneira para expressar suas angústias de perda, elaborar situações que foram traumáticas e dolorosas e reviver situações que foram penosas, para modificá-las de acordo com seus gostos e interesses, repetir momentos prazerosos e vivenciar situações que não são permitidas na vida real.

O brinquedo possui muitas das características dos objetos reais, mas, pelo seu tamanho, pelo fato de que a criança exerce domínio sobre ele, pois o adulto outorga-lhe a qualidade de algo próprio e permitido, transforma-se no instrumento para o domínio de situações penosas, difíceis, traumáticas, que se engendram na relação com os objetos reais. Além disso, o brinquedo é substituível e permite que a criança repita, à vontade, situações prazenteiras e dolorosas que, entretanto, ela por si mesma não pode reproduzir no mundo real. (ABERASTURY, 1992, p.15).

Winnicott (1982) aponta que a criança adquire experiência por meio de suas brincadeiras, da mesma forma que o adulto evolui por meio de seu contato com o mundo. Dessa maneira, a brincadeira infantil contribui para uma integração da personalidade e constitui uma fase de extrema importância do desenvolvimento da criança, pois "[...] fornece uma organização para a iniciação de relações emocionais e assim propicia o desenvolvimento de contatos sociais." (WINNICOTT, 1982, p.163).

Aberastury (1992) ressalta que o não brincar no momento adequado pode ser considerado um fator preocupante, que requer uma atenção especial. Do mesmo modo, para Winnicott (1982), é essencial que incentivemos a capacidade de brincar que a criança possui.

Um brinquedo,

[...] é uma parcela do mundo real; contudo, se for oferecido da melhor maneira e na ocasião mais apropriada pela pessoa mais adequada, terá um significado para a criança que deveríamos ser capazes de compreender e aceitar. (WINNICOTT, 1982, p.77).

De acordo com Aberastury (1992), o fato de o adulto considerar o brinquedo um objeto aceitável e que pertence à criança permite que ela se organize internamente, por meio da ação.

Ao brincar, a criança desloca para o exterior seus medos, angústias e problemas internos, dominando-os por meio da ação. Repete no brinquedo todas as situações excessivas para seu ego fraco e isto lhe permite, devido 
ao domínio sobre os objetos externos a seu alcance, tornar ativo aquilo que sofreu passivamente, modificar um final que lhe foi penoso, tolerar papéis e situações que seriam proibidas na vida real tanto interna como externamente e também repetir à vontade situações prazerosas. (ABERASTURY, 1992, p.15).

É importante que os brinquedos disponibilizados para a criança sejam resistentes, para que não se quebrem com facilidade, pois isto acarreta frustração e angústias. Mas se caso virem a quebrar, é indispensável que o adulto auxilie a criança no conserto, pois ela precisa exercer sua capacidade de reparação para que não se sinta culpada.

Conforme Winnicott (1982), o brincar permite que a criança entre em contato com a sua realidade íntima psíquica pessoal, por isso, em suas atividades, poderemos encontrar expressões de amor e agressividade.

[...] a criança aprecia concluir que os impulsos coléricos ou agressivos podem exprimir-se num meio conhecido, sem o retorno do ódio e da violência do meio para a criança. Um bom meio ambiente, sentiria a criança, deveria ser capaz de tolerar os sentimentos agressivos, se estes fossem expressos de uma forma mais ou menos aceitável. Deve-se aceitar a presença da agressividade, na brincadeira da criança, e esta sente-se desonesta se o que está presente tiver de ser escondido ou negado. (WINNICOTT, 1982, p.161).

Assim, Winnicott (1982) acredita que ao manifestar seus impulsos destrutivos no brinquedo, a criança se sente confortada, pois, os sentimentos agressivos expressos não retornam do objeto para ela. Além do mais, o brinquedo permite que a criança transfira os sentimentos agressivos que possui em relação a alguém para um objeto, assim, ela descarrega seus impulsos coléricos sobre uma forma simbólica e substituível que atende suas necessidades.

É essencial que o adulto aprove ou, ao menos, tolere a agressividade durante a brincadeira, pois, do contrário, acarretará frustrações e angústias na criança, e, dessa maneira, a finalidade de elaboração das angústias na brincadeira não será alcançada, ao invés disso, gerará mais angústias.

Winnicott (2005) considera que a capacidade de construir apresenta-se para a criança como uma forma importante para ela lidar com sua agressividade. Assim, o brincar construtivo significa um sinal de saúde, pois “[...] em condições ambientais favoráveis, um impulso construtivo está relacionado com a aceitação pessoal, por parte da criança, da responsabilidade pelo aspecto destrutivo da sua natureza." (WINNICOTT, 2005, p.107). Esse brincar construtivo 
surge gradualmente no decorrer do desenvolvimento da criança, estando na dependência das experiências de vida.

Para Winnicott (1982), é importantíssimo para o desenvolvimento emocional da criança que os pais demonstrem uma disponibilidade lúdica para com seus filhos, pois tais atividades entre pais e filhos constituem as melhores relações entre ambos. O tempo que os pais dedicam aos seus filhos é imprescindível para um desenvolvimento saudável dos mesmos, já que a relação afetiva é a base para que, futuramente, eles possam se tornar adultos saudáveis emocionalmente.

Portanto, é importante que a brincadeira faça parte da vida da criança, tanto no âmbito escolar, como no âmbito familiar. Segundo Winnicott (1982), a compreensão que a criança terá do mundo dependerá de como ele foi apresentado a ela no decorrer do seu desenvolvimento. Nesse aspecto, a atividade lúdica desempenha um papel essencial, pois ajuda a criança a enxergar a si própria e ao mundo.

Winnicott (1982) ressalta que os adultos precisam ser conscientizados dos benefícios que o brincar fornece para o desenvolvimento emocional da criança.

As experiências tanto externas como internas podem ser férteis para o adulto, mas para a criança essa riqueza encontra-se principalmente na brincadeira e na fantasia. Tal como as personalidades dos adultos se desenvolvem através de suas experiências da vida, assim as das crianças evoluem por intermédio de suas próprias brincadeiras e das invenções de brincadeiras feitas por outras crianças e por adultos. (WINNICOTT, 1982, p.163).

Aberastury (1992, p.51) defende que "Todos aqueles brinquedos que, pela simplicidade, facilitam a projeção de fantasias, são os quem têm mais possibilidades de ajudá-la na função específica do brinquedo, que é a de elaborar situações traumáticas."

Tendo em conta essas relevantes características do brincar, é imprescindível que a criança seja reconhecida como um ser humano total, que possui sentimentos e necessidades que precisam ser respeitadas e atendidas, e reconhecermos a relevância do brincar na expressão e elaboração de sentimentos, pois, ao banalizarmos os sentimentos da criança e suas brincadeiras, podemos estar comprometendo ou dificultando o seu desenvolvimento emocional.

\section{DISCUSSÃO}

Tendo ciência dos inúmeros benefícios que as atividades lúdicas podem oferecer às crianças, pode-se refletir sobre as suas contribuições no espaço escolar. 
Conforme se explicitou, o ato do brincar, na perspectiva psicanalítica, representa uma forma de comunicação profunda e abrangente, pois, a criança faz do brinquedo um instrumento para manifestar seus afetos, simbolizar e elaborar suas angústias e revelar sua realidade interior. O brincar representa, portanto, uma prática saudável e essencial para o desenvolvimento emocional da criança, pelo fato de permitir que ela entre em contato com seu mundo interno, de forma a melhor compreendê-lo e elaborá-lo. O simbolismo presente no brincar contribui para que a criança atribua sentido aos aspectos simbólicos presentes no contexto escolar, como, por exemplo, o uso de letras e números.

Ao desenvolver atividades lúdicas com crianças que apresentam condutas agressivas, o professor pode possibilitar que estas encontrem uma maneira de descarregar e lidar com suas emoções e tendências agressivas, sem que se sintam culpadas, proporcionando o alívio de suas tensões pré-conscientes e inconscientes e diminuindo o medo de suas tendências destrutivas. Assim, haverá uma contribuição para a tranquilidade das mesmas, podendo se concentrarem mais nas atividades escolares.

Do mesmo modo, crianças extremamente tímidas podem encontrar na ludicidade a oportunidade de expressarem suas emoções, angústias e conflitos, o que poderá auxiliar o relacionamento delas com os demais.

\section{CONCLUSÃO}

Nas brincadeiras a criança encontra a possibilidade de elaborar seus conflitos e suas angústias, assumir papéis e vivenciar situações que não são permitidas na vida real. Esse conforto encontrado na atividade lúdica pode trazer impactos benéficos aos alunos cujas dificuldades emocionais estejam prejudicando sua atenção em sala de aula, seu adequado aprendizado e relacionamento com as demais crianças.

Portanto, acredita-se que o brincar pode ser um excelente aliado tanto para o professor - em sua tarefa de educar - quanto para as crianças e pais, em uma fase de suprema importância, na qual elas estão se desenvolvendo mentalmente e formando a sua personalidade.

\section{REFERÊNCIAS}

ABERASTURY, Arminda. A criança e seus jogos. 2 ed. Porto Alegre: Artemed, 1992. 88p.

LÜDKE, M.; ANDRÉ, M. E. D. A. Pesquisa em educação: abordagens qualitativas. São Paulo: EPU, 1986. 
FREUD, Sigmund. Além do princípio de prazer (1920). In: FREUD, Sigmund. Obras completas de Sigmund Freud. Rio de Janeiro: Imago, 1976, v. 23. p.13 - 75.

KLEIN, Melanie. A técnica psicanalítica através do brincar: sua história e significado. In: KLEIN, Melanie. Inveja e gratidão e outros trabalhos (1946 - 1963). Rio de janeiro: Imago, 1991. p. 149 168.

WINNICOTT, D. W. A criança e o seu mundo. 6 ed. Rio de Janeiro: LTC- Livros Técnicos e Científicos Editora S.A., 1982.

WINNICOTT, D. W. O brincar e a realidade. s.e. Rio de Janeiro: Imago, 1975. 203p.

WINNICOTT, D. W. Privação e delinqüência. 4 ed. São Paulo: Martins Fontes, 2005. 